\title{
Gaucher disease type 2
}

INSERM

\section{Source}

INSERM. (1999). Orphanet: an online rare disease and orphan drug data base. Gaucher disease type 2. ORPHA:77260

Gaucher disease type 2 is the acute neurological form of Gaucher disease (GD; see this term). It is characterized by early-onset and severe neurological involvement of the brainstem, associated with an organomegaly and generally leading to death before the age of 2 . 